\title{
Recessions, Retirement, and Social Security
}

\author{
Courtney C. Coile \\ Department of Economics \\ Wellesley College \\ 106 Central St. \\ Wellesley, MA 02481 \\ (781) 283-2408; phone \\ (781) 283-2177; fax \\ ccoile@wellesley.edu
}

Phillip B. Levine

Department of Economics

Wellesley College

106 Central St.

Wellesley, MA 02481

(781) 283-2408; phone

(781) 283-2177; fax

plevine@wellesley.edu 


\section{INTRODUCTION}

The economic crisis that began in 2008 had multiple implications for retirement behavior. The stock market crash may have caused some individuals to defer retirement because of losses they experienced in their 401(k)-type retirement plans. The spike in unemployment may have led others to "retire" sooner in response to a job loss or the inability to find work. Coile and Levine (2007, 2009, and 2010) provide evidence of both types of behavior. By the end of 2010, however, the stock market had nearly rebounded to pre-crash levels. Although the market still may be below what individuals had expected and there may have been some short-term impacts, the market's sharp rise has substantially diminished the importance of this part of the story. The weakness in the labor market, however, continues to be extensive and persistent. The purpose of this analysis is to focus on its implications for retirement and retiree well-being in the coming years.

High unemployment has the potential to significantly alter the well-being of older workers, both in the present and for the remainder of their lives. If an older worker loses his or her job, finding a new one may be even more difficult than it is for a younger worker. The older worker's relatively short time horizon in the labor force may reduce their own or a prospective employer's willingness to invest in additional human capital. If specific capital has been lost, the wage a new employer may offer may be considerably below the worker's previous wage, reducing the likelihood of an offer being extended or accepted. For these reasons and others, the future employment prospects of a laid off older worker may be bleak.

In such an environment, Social Security benefits may be a lifeline for these workers. But while taking up benefits when they first become available at age 62 may help a laid off older worker pay the bills, it also means reduced income for the remainder of the worker's life, since 
monthly benefits are reduced (increased) for early (late) claiming so as to provide roughly the same expected lifetime benefits regardless of the age at which benefits are claimed. The negative impact of early claiming on retiree well-being may be particularly pronounced for low socioeconomic status individuals, who rely heavily on Social Security to make ends meet.

The purpose of this paper is to examine the impact of labor market fluctuations on the retirement behavior and Social Security income of older individuals. Specifically, we use 30 years of data from the March Current Population Survey to measure the impact of a weak labor market on the labor force status and Social Security receipt of individuals between the ages of 55 and 69. We also use data from the 2000 Census and 2001, 2002, and 2006-2009 American Community Surveys (ACS) to examine whether labor market conditions around the time of retirement affect the subsequent income of retirees in their 70s. We find support for the notion that workers are more likely to leave the labor force, to collect Social Security earlier, and to have lower Social Security retirement income later in life when they face a recession around the time of retirement. The impact of such an event is greatest for the less-educated, who are more susceptible to job loss and rely more heavily on Social Security to support them in retirement.

\section{DATA AND METHODS}

We rely on 30 years of data (1980-2009) from the March Current Population Survey (CPS) in our analysis of labor market conditions on labor force status and Social Security receipt. The CPS is the leading survey of labor market activity in the United States. The monthly CPS survey asks questions about the respondent's involvement in the labor market around the time of survey and collects demographic data. In March of each year, a supplement is administered that includes questions about income receipt, including from Social Security, in the preceding calendar year. Each March CPS provides sample sizes of 130,000 to 215,000. We focus on 
those between the ages of 55 and 69. As we describe subsequently, to be consistent with our analysis of the Census/ACS data, we also restrict the sample to men. This leaves us with a final sample size of 292,093 men ages 55 to 69 over the period 1980 through 2009.

Our analysis of retirement income for individuals in their 70s relies on data from the 2000 Census and the 2001, 2002, and 2006-2009 American Community Surveys (ACS). ${ }^{1}$ The Census provides a very large number of observations: 5 percent of the U.S. population. To obtain time series variation, we augment these data with the ACS data. The ACS is modeled after the Census, with similar variables and coding, and contains data for one percent of the population (starting in 2005; earlier samples are smaller). We use unified Census/ACS extracts from the Minnesota Population Center’s IPUMS USA project (Ruggles, et al., 2009).

We place three sample restrictions on our data. First, our focus is on retirement income, so we restrict the sample to those individuals who have already left the labor force. This is not a major constraint given the age composition of the sample. More importantly, we restrict our attention to the incomes of men. We do so because women in these birth cohorts are likely to receive Social Security payments based on their husbands' earning records, either because they do not qualify for retired worker benefits or because their dependent spouse benefits are greater. It will thus be the market conditions present around the time that the husband retired that matter,

${ }^{1}$ Alexander, et al. (2010) cautions users about the potential that the age and sex variables in the 2000 Census and some subsequent American Community Surveys may include some miscoded data due to erroneous disclosure avoidance procedures. To date, released versions of the 2000 Census and 2006 ACS contain corrected age data. We do not use data from the 2003 through 2005 ACS surveys because no corrected data are available. 
but for those women who have become widowed, we have no data on the age of the husband. Finally, we focus our attention on those who report some income from Social Security. With over 90 percent of respondents in their 70s in this category, those who report no such income are likely not eligible to receive it, so their income from this source would not be altered by labor market conditions. We are left with a final sample of 570,679 men ages 70 to 79 . We augment the CPS and Census/ACS samples with state-level unemployment rate data from the Bureau of Labor Statistics.

Our statistical models are identified based on the differing historical experiences of individuals born into different birth cohorts. In essence, we treat labor market conditions around the time of retirement as a draw that is randomly assigned to individuals. In our analysis of labor force status and Social Security receipt using March CPS data, the availability of state-level data on labor market conditions enables us to implement traditional quasi-experimental methods in regression models that include both state and year fixed effects along with age fixed effects to control for differential patterns in outcomes by age. We estimate linear probability models where the outcome variables indicate whether an individual is out of the labor force and whether he is collecting Social Security benefits as a function of the state unemployment rate in the preceding calendar year (to allow for the change in labor force status to have occurred by the survey date), holding constant these fixed effects along with demographic characteristics (race/ethnicity, marital status, educational attainment). Because the availability of Social Security benefits at age 62 suggests that responses to a weak labor market may differ by age, we interact the unemployment rate with a series of categorical age variables. It is our hypothesis that individuals will be more likely to withdraw from the labor force in response to a recession if 
they are at least 62 years old. Moreover, any impact on Social Security receipt should not begin until that age since retirement benefits are not available before then. ${ }^{2}$

Our models of income for retirees in their 70s similarly rely on the plausibly exogenous variation generated by whether an individual is unlucky enough to approach retirement age during a recession. We estimate regression models where the dependent variable is the natural log of Social Security income and the key explanatory variables are the average historical unemployment rates at earlier ages (55-57, 58-59, 60-61, 62-64, and 65-69). The unemployment rates that an individual experienced can almost be thought of as a historical accident. Along with these unemployment rates, we also control for the contemporaneous unemployment rate and state, age, and survey year fixed effects. The idea is to see if labor market conditions around the time of retirement (and we are agnostic regarding exactly what that age is) affect the income of retirees ten or so years later.

\section{RESULTS}

Table 1 presents the results of our analysis of March CPS data examining the impact of labor market conditions on labor force status and Social Security receipt. The top panel of the table focuses on the likelihood that men between the ages of 55 and 69 have dropped out of the labor force. We examine this outcome for all men in this age group as well as for sub-samples by level of educational attainment (high school dropouts, high school graduates, and those who have attended any college regardless of whether or not they have graduated). Each model

2 The impact may begin somewhat before age 62 because the survey does not distinguish whether Social Security receipt is attributable to retirement or disability. Autor and Duggan (2003) have shown that some older individuals rely on Social Security disability benefits to provide income support when times are tough. 
interacts last year's annual average unemployment rate with a set of age categories to assess whether labor market conditions have a differential impact on labor force status at different ages. The base group for this comparison is men aged 55 to 57 , so these interactions can be interpreted as the differential impact of unemployment on the specified age group relative to this younger group. Since the younger group is less likely to have retired, it serves as something like a control group that can capture the broader link between aggregate labor market conditions and an individual's labor force status, abstracting from the impact on retirement.

The results indicate that a higher unemployment rate leads to a greater probability of withdrawal from the labor force (retirement) as workers age, particularly after age 62 when Social Security benefits are available. A one percentage point increase in the unemployment rate is estimated to increase the number of 62 to 64 and 65 to 69 year old workers who are out of the labor force by over a full percentage point. The effects are stronger for high school dropouts and high school graduates than for those with at least some college education. The p-value on a test of the equality of coefficients at ages 62-64 across groups is 5.7 percent.

We find similar patterns when we focus our attention on the likelihood of Social Security receipt in the lower panel of the table. Again, a higher unemployment rate increases Social Security receipt beginning at age 62 and mainly for workers in the two lower educational attainment groups. Interestingly, the magnitude of the effect at ages 62-64 is larger than it is at ages 65-69 for Social Security receipt, but that is not true for labor force status. A plausible explanation for this is that as workers age into their late 60s, they commence receipt of Social Security benefits regardless of their labor force status, lessening the importance of labor market fluctuations on receipt at those older ages.

Table 1: Impact of Labor Market Conditions on Older Workers’ Labor Force Status 
and Social Security Receipt (standard errors in parentheses)

\begin{tabular}{|c|c|c|c|c|}
\hline & & High School & High School & Attended/Completed \\
\hline & All & Dropouts & Graduates & College \\
\hline \multicolumn{5}{|c|}{ Outcome: Out of Labor Force } \\
\hline Unemployment rate* & 0.083 & 0.214 & 0.238 & -0.116 \\
\hline age $58-59$ & $(0.138)$ & $(0.296)$ & $(0.236)$ & $(0.180)$ \\
\hline Unemployment rate* & 0.294 & 0.641 & 0.350 & 0.0850 \\
\hline age 60-61 & $(0.160)$ & $(0.294)$ & $(0.264)$ & $(0.229)$ \\
\hline Unemployment rate* & 1.091 & 1.113 & 1.323 & 0.514 \\
\hline age 62-64 & $(0.184)$ & $(0.318)$ & $(0.233)$ & $(0.290)$ \\
\hline Unemployment rate* & 1.221 & 1.433 & 1.770 & 0.344 \\
\hline age 65-69 & $(0.186)$ & $(0.297)$ & $(0.218)$ & $(0.294)$ \\
\hline \multicolumn{5}{|c|}{ Outcome: Social Security Receipt } \\
\hline Unemployment rate* & 0.040 & 0.177 & -0.039 & -0.104 \\
\hline age 58-59 & $(0.089)$ & $(0.266)$ & $(0.148)$ & $(0.091)$ \\
\hline Unemployment rate* & 0.181 & 0.508 & -0.063 & 0.053 \\
\hline age $60-61$ & $(0.147)$ & $(0.290)$ & $(0.188)$ & $(0.144)$ \\
\hline Unemployment rate* & 0.894 & 1.218 & 0.741 & 0.175 \\
\hline age 62-64 & $(0.205)$ & $(0.305)$ & $(0.221)$ & $(0.287)$ \\
\hline Unemployment rate* & 0.220 & 1.070 & 0.503 & -0.739 \\
\hline age 65-69 & $(0.167)$ & $(0.232)$ & $(0.232)$ & $(0.242)$ \\
\hline \# obs. & 292,093 & 77,387 & 95,350 & 119,356 \\
\hline
\end{tabular}


Notes: All estimates come from linear probability models that also include the current and lagged annual unemployment rate without age interactions, race/ethnicity, marital status, and exact age, state of residence, and year fixed effects. Reported coefficients are multiplied by 100 . Standard errors are clustered at the state level.

Table 2 reports the results of our analysis of the effect of labor market conditions around the time of retirement on the income of retired men ages 70 to 79 . We focus on income received from Social Security in the top panel and on total personal income in the bottom panel. In both cases, we report coefficients on the historical unemployment rates that these individuals experienced in their late 50s through their 60s, using the average rate at specified ages. Models are estimated for all men and for sub-samples by level of educational attainment.

The results suggest that experiencing a recession in the years leading up to retirement lowers subsequent retirement income. This finding is particularly evident for Social Security income, for less educated workers, and for labor market events that take place at or after age 62. Overall, experiencing a one percentage point increase in the unemployment rate at ages 62-64 reduces income from Social Security by 0.435 percent. We interpret this magnitude subsequently. As anticipated, the effect of unemployment at ages 62-64 on retiree income falls as education rises, although imprecision prevents us from rejecting the null hypothesis that the coefficients are equal. One puzzling finding in this table is that higher unemployment at ages 65-69 is associated with significantly higher Social Security benefits for retired men in their 70s. Although we have no specific explanation for this finding, we are at least somewhat comforted by the fact that the coefficient for high school dropouts is small and statistically insignificant. 
When we focus on total income, we find that the only significant effect of historical unemployment on subsequent retiree income is the effect of unemployment at ages 60 to 61 for high school dropouts. That coefficient has a p-value of .085. The equivalent coefficient for age 62-64 unemployment is of a comparable magnitude, but it is not quite significant at even the 10 percent level. Overall, the findings from Table 2 provide some support for our hypotheses, but they are not as strong as they could be.

A final way to interpret these findings is by assessing whether the magnitude of the coefficients is reasonable. To address this, we can combine results from the bottom panel of Table 1 regarding Social Security receipt around retirement age and the top panel of Table 2 regarding Social Security income for workers in retirement. Consider, for instance, the impact of a one percentage point increase in the unemployment rate at ages 62-64 for high school dropouts. The results in Table 1 suggest that they would be 1.218 percentage points more likely to receive Social Security at that age. The results in Table 2 suggest that subsequent Social Security income in retirement is estimated to fall by 0.517 percentage points. If that one point increase in unemployment led 1.218 percent more workers to collect Social Security at ages 62-64 and that change led to a 0.517 percent reduction in aggregate receipt of Social Security income, then this suggests that the average worker who began Social Security receipt as a result of the increase in unemployment experienced a 42 percent reduction $(0.517 / 1.218=0.424)$ in Social Security benefits. A similar analysis for high school graduates indicates that the average incremental Social Security recipient would face a 53 percent benefit reduction. To put these estimates in perspective, for individuals in these birth cohorts, claiming benefits at 62 rather than 65 would be 
associated with a 20 percent reduction in their Social Security benefit. ${ }^{3}$ On that basis, our estimates are rather high. However, we have estimated 95 percent confidence intervals for both estimates using the delta method and both include this 20 percent figure.

Table 2: Long-Term Impact of Labor Market Conditions on the Amount of Social Security Received by Retirees

(standard errors in parentheses)

\begin{tabular}{ccccc}
\hline \hline & & High School & High School & Attended/Completed \\
& All & Dropouts & Graduates & College \\
\hline Unemployment rate at & 0.186 & 0.095 & 0.153 & 0.206 \\
Oge 55-57 & $(0.069)$ & $(0.114)$ & $(0.117)$ & $(0.179)$ \\
Unemployment rate at & -0.003 & 0.203 & 0.056 & -0.099 \\
age 58-59 & $(0.105)$ & $(0.139)$ & $(0.127)$ & $(0.220)$ \\
Unemployment rate at & -0.024 & -0.275 & 0.062 & 0.179 \\
age 60-61 & $(0.102)$ & $(0.140)$ & $(0.143)$ & $(0.255)$ \\
Unemployment rate at & -0.435 & -0.517 & -0.396 & -0.206 \\
age 62-64 & $(0.121)$ & $(0.177)$ & $(0.116)$ & $(0.300)$ \\
Unemployment rate at & 0.591 & 0.194 & 0.557 & 1.115 \\
age 65-69 & $(0.143)$ & $(0.193)$ & $(0.162)$ & $(0.383)$ \\
\hline
\end{tabular}

${ }^{3}$ These rules have since changed so that now a worker who retires at 62 rather than 66 receives a 25 percent reduction in their benefit. 


\begin{tabular}{|c|c|c|c|c|}
\hline \multicolumn{5}{|c|}{ Outcome: Total Income } \\
\hline Unemployment rate at & -0.018 & 0.131 & -0.001 & -0.306 \\
\hline age $55-57$ & $(0.096)$ & $(0.184)$ & $(0.129)$ & $(0.140)$ \\
\hline Unemployment rate at & 0.084 & 0.122 & 0.169 & -0.009 \\
\hline age 58-59 & $(0.084)$ & $(0.172)$ & $(0.138)$ & $(0.162)$ \\
\hline Unemployment rate at & -0.156 & -0.372 & -0.087 & -0.212 \\
\hline age $60-61$ & $(0.131)$ & $(0.202)$ & $(0.174)$ & $(0.217)$ \\
\hline Unemployment rate at & -0.109 & -0.332 & 0.025 & -0.133 \\
\hline age $62-64$ & $(0.135)$ & $(0.217)$ & $(0.205)$ & $(0.226)$ \\
\hline Unemployment rate at & 0.248 & 0.379 & 0.346 & -0.083 \\
\hline age $65-69$ & $(0.273)$ & $(0.327)$ & $(0.344)$ & $(0.256)$ \\
\hline \# obs. & 570,679 & 154,710 & 205,848 & 210,121 \\
\hline \multicolumn{5}{|c|}{ 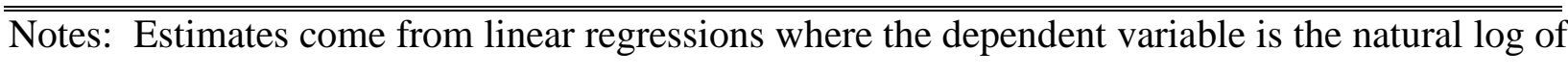 } \\
\hline \multicolumn{5}{|c|}{$\begin{array}{l}\text { Social Security benefits received. Other control variables include the contemporaneous annual } \\
\text { unemployment rate, race/ethnicity, marital status, and age, state of residence, and year fixed }\end{array}$} \\
\hline
\end{tabular}

\section{CONCLUSIONS}

This analysis began by hypothesizing that the current high rate of unemployment in the U.S. will lead some older individuals to withdraw from the labor force early (particularly after age 62), to claim Social Security benefits early, and to subsequently receive lower retirement income (as a result of earlier claiming of Social Security benefits). Our analysis of historical data provides evidence supporting much of this conjecture. We find that individuals ages 62 and 
older are more likely to withdraw from the labor force when the unemployment rate is high and are also more likely to be receiving Social Security benefits. These effects are strongest for less educated workers. Our analysis of retiree income is less persuasive, but still offers evidence that is suggestive in its support of our hypotheses. Taken as a whole, we believe that these findings highlight the importance of focusing on the well-being of older workers who have lost their jobs in the present recession and may suffer lower income for many years as a result.

\section{References}

Alexander, J. Trent, Michael Davern, and Betsey Stevenson (2010). “Inaccurate Age and Sex

Data in the Census PUMS files: Evidence and Implications.” NBER working paper 15703. Autor, David H. and Mark G. Duggan (2003). “The Rise in the Disability Rolls and the Decline in Unemployment.” Quarterly Journal of Economics, 118(1): 157-205.

Coile, Courtney C. and Phillip B. Levine (2010). Reconsidering Retirement: How Losses and Layoffs affect Older Workers. Washington, DC: Brookings Institution Press.

Coile, Courtney C. and Phillip B. Levine (2009). “The Market Crash and Mass Layoffs: How the Current Economic Crisis May Affect Retirement.” National Bureau of Economic Research, Working Paper 15395.

Coile, Courtney C. and Phillip B. Levine (2007). “Labor Market Shocks and Retirement: Do Government Programs Matter?” Journal of Public Economics. 91(10): 1902-1919. Steven Ruggles, Matthew Sobek, Trent Alexander, Catherine A. Fitch, Ronald Goeken, Patricia Kelly Hall, Miriam King, and Chad Ronnander (2009). Integrated Public Use Microdata Series: Version 4.0 [Machine-readable database]. Minneapolis, MN: Minnesota Population Center [producer and distributor]. 